\title{
Preservation of mesophilic mixed culture for anaerobic palm oil mill effluent treatment by convective drying methods
}

Chin, S. K. ${ }^{\text {**, Tan, D. T. }}{ }^{b}$, Tan, H. M. ${ }^{\text {b }}$ Poh, P. E. ${ }^{b}$

${ }^{a}$ Chemical Engineering, Newcastle University in Singapore, 537 Clementi Road \#6-01, SIT@Ngee Ann Polytechnic Building, Singapore 599493, Singapore

b Chemical Engineering Discipline, School of Engineering, Monash University Malaysia, Jalan Lagoon Selatan, 47500, Selangor Darul Ehsan, Malaysia

*E-mail of the corresponding author: kent.chin@newcastle.ac.uk

\begin{abstract}
While anaerobic digestion is a reliable method that treats the waste and produces renewable biomethane fuel, the necessary sludge in liquid form is difficult to handle due to the constant biogas generation. Therefore, this study investigates the possibility of convective air drying, namely heat pump and hot air circulation oven as preservation methods for anaerobic microbial sludge. Drying was conducted at various temperatures, ranging from $22^{\circ} \mathrm{C}$ to $70^{\circ} \mathrm{C}$. The study found that heat pump drying at $22^{\circ} \mathrm{C}$ resulted in highest COD removal of $55.3 \%$ as well as the least log reduction in methanogens and anaerobes at 1.4 and 2.4 , respectively.
\end{abstract}

Keywords: Chemical Oxygen Demand (COD); Heat pump drying; Hot air drying; Log reduction; Methane yield 


\section{Introduction}

Palm oil mill effluent (POME) is liquid waste containing oil, plant debris, and nutrients produced from palm oil milling process. In Malaysia, the most widely used effluent treatment scheme is the anaerobic/facultative ponds. Anaerobic digestion is the decomposition of organic material whereby the end products are biogas and sludge. This process is desirable due to low costs and low energy demand involved besides producing a biologically stable final product with good fertilizing properties as well high nutrient content. However, Difficulty in supplying the solid-liquid mixture of microbial seed sludge for anaerobic treatment of POME has raised several issues that must be overcome in order to promote the practicality of this treatment option. Main concerns include limitations in storage and transportation due to constant biogas generation from the anaerobic digestion ${ }^{[1]}$. Drying of the seed sludge allows easier storage of additional sludge as the mass and volume are greatly reduced due to majority of water content evaporated ${ }^{[2]}$. In addition to space conservation, the dried product can be more easily transported in its inactive form, where biodegradation and biogas production is halted in its dormant form which prevents fire hazard and risk of over-pressurisation ${ }^{[3]}$. There have been many studies conducted for the preservation of microorganisms. Numerous studies have shown that high cell viability of pure cultures can be achieved using freeze drying technique ${ }^{[4]}$. Despite its wide applicability, this method is cost intensive and requires long drying time which could be harmful to several delicate microorganisms ${ }^{[5]}$. Thus, relatively inexpensive convective air drying has been considered as promising alternative to address problems encountered in freeze drying.

To date, research on the application of convective air drying for microorganism preservation, or more specifically for mixed culture preservation, is rather scarce and largely limited to agricultural and dairy industry. Hence, this study aims to develop dried mesophilic mixed culture from economical convective air drying methods, namely heat pump and hot air circulation oven. Various drying conditions were also investigated to achieve the highest possible cell survival, methane yield, and treatment performance during treatment of POME.

\section{Materials and Methods}

\subsection{Sample preparation}

Seed sludge and palm oil mill effluent (POME) were obtained from the palm oil mill at Seri Ulu Langat in Dengkil, Malaysia. During cultivation, intermittent feeding of POME as substrate was done in order to maintain the microbial population in the seed sludge. 


\subsection{Cultivation of mixed culture in UASB batch reactor}

An up-flow anaerobic sludge blanket (UASB) reactor with an effective volume of $2.5 \mathrm{~L}$ as shown in Fig.1 (separate attachment) was used to cultivate mesophilic sludge. To start-up, $625 \mathrm{~mL}$ of seed sludge which represents $25 \%$ of the working volume is fed to the tank, while the remaining $75 \%$ consists of diluted POME. $\mathrm{pH}$ of the system was maintained in the range of 6.8-7.2 through the addition of $2 \mathrm{~mol} / \mathrm{L} \mathrm{NaHCO}_{3}$ to ensure satisfactory methanogenic activity ${ }^{[6]}$. Treated effluent was collected by letting the mixture in the bioreactor to settle for 30 minutes. After which the top portion of the mixture was collected as supernatant and sent for qualitative and quantitative analysis. COD removal is used as criteria for increasing load in the feed to maintain the effectiveness of the system, especially when COD removal is higher than $80 \%$ or when there is less than $5 \%$ increase for 3 consecutive readings. The then matured mixed culture seed sludge was extracted from the batch reactor for drying procedure.

\subsection{Drying methods}

$25 \mathrm{~g}$ of the mesophilic mixed culture sludge was extract from the bioreactor and used to perform drying experiment in three replicates. The sludge was dried until equilibrium moisture content (EMC) by using different drying methods as described in the following sections.

\subsubsection{Heat pump drying}

A laboratory scale heat pump dryer fabricated by I-Lab Sdn. Bhd., Selangor, Malaysia was used in this research. The heat pump dryer consists of a drying chamber of dimensions 0.8 $\mathrm{m} \times 0.6 \mathrm{~m} \times 0.6 \mathrm{~m}$ and a heat pump system. Mild temperature dehumidifier air produced by the heat pump system was used as a drying medium to dry the sludge in the chamber. The dryer operated at temperature of $22^{\circ} \mathrm{C}$ and relative humidity (RH) of $38.1 \%$. In addition, the dryer is equipped with an auxiliary heater which can be switched on to give drying temperature of $32^{\circ} \mathrm{C}$ and $\mathrm{RH}$ of $29.5 \%$. The average air velocity in the drying chamber was recorded at $2 \mathrm{~m} / \mathrm{s}$ across the two drying conditions.

\subsubsection{Hot air circulation oven drying}

Hot air circulation oven (Memmert UFB500) was used to conduct drying of sludge at average temperature and relative humidity of $40.0^{\circ} \mathrm{C}, 50.0^{\circ} \mathrm{C}, 60.0^{\circ} \mathrm{C}, 70.0^{\circ} \mathrm{C}$ and $19.9 \%$, $16.1 \%, 7.4 \%, 4.7 \%$, respectively. The drying chamber has a dimension of $53 \mathrm{~cm} \times 47 \mathrm{~cm} \times$ $39 \mathrm{~cm}$ where air is circulated by an air turbine with measured average velocity of $1.9 \mathrm{~m} / \mathrm{s}$ for all drying temperatures. 


\subsection{Drying rate and moisture diffusivity}

The initial moisture content $\left(\mathrm{M}_{0}\right)$, moisture content at a given drying time $\mathrm{t}\left(\mathrm{M}_{\mathrm{t}}\right)$, equilibrium moisture content $\left(\mathrm{M}_{\mathrm{eq}}\right)$, moisture ratio $\left(\mathrm{MR}_{\mathrm{t}}\right)$ and drying rate $(\mathrm{R})$ of the mesophilic mixed culture sludge were calculated by equations (1) - (5) whereas the moisture diffusivity $\left(\mathrm{D}_{\text {eff }}\right)$ of the samples was determined using Fick's second model (equation (6)).

$$
\begin{aligned}
& M_{0}=\frac{W_{0}-W_{d}}{W_{d}} \quad(1) ; M_{t}=\frac{W_{t}-W_{d}}{W_{d}} \quad(2) ; M_{e q}=\frac{W_{e q}-W_{d}}{W_{d}} \quad(3) ; M R_{t}=\frac{M_{t}-M_{e q}}{M_{0}-M_{e q}} \\
& R=\frac{W_{d}}{A_{s}}\left|\frac{F_{t+1}-F_{t}}{t_{i+1}-t_{i}}\right| \quad(5) ; M R=\frac{8}{\pi^{2}}\left[\sum_{n=0}^{99} \frac{1}{(2 n+1)^{2}} \exp \left(\frac{-(2 n+1)^{2} \pi^{2} D_{e f f} t}{l^{2}}\right)\right]
\end{aligned}
$$

Where $W_{0}, W_{t}, W_{d}$, and $W_{e q}$, refer to initial weight of the sample (kg), weight of the sample in the middle of drying process at time $t(\mathrm{~kg})$, bone dry weight of the sample $(\mathrm{kg})$, and equilibrium weight of the sample $(\mathrm{kg})$, respectively. $A_{s}$ is denoted as the surface area of the samples $\left(\mathrm{m}^{2}\right), F_{t}$ is the free moisture content of the sample at time $t\left(\mathrm{~kg} \mathrm{H} \mathrm{H}_{2} \mathrm{O} / \mathrm{kg}\right.$ dry material). $\mathrm{l}, \mathrm{t}$ and $\mathrm{n}$ are the sample's thickness (m), drying time (s) and a positive integer, respectively.

\subsection{Quality analysis}

The quality of dried mixed culture mesophilic sludge was evaluated by assessing the viability of microorganisms after drying. To do that, the dried mixed culture was first rehydrated before it can be evaluated for cell survival, COD removal, and methane yield.

\subsubsection{Rehydration of mixed culture}

Rehydration was performed by adding distilled water in the amount equivalent to that lost during drying process and agitated in incubator shaker at $37^{\circ} \mathrm{C}$ and $250 \mathrm{rpm}$ for 18 hours. The resultant rehydrated mixed cultures were then evaluated for cell survival by obtaining the most probable number (MPN) of microorganisms contained in the sample. The rehydrated sludge was also evaluated for its performance in treating POME through assessment of the COD removal and methane yield.

\subsubsection{Cell survival}

MPN enumeration was conducted to obtain the cell count of microorganisms following drying process. Culture medium was prepared by dissolving 30 grams of tryptic soy broth (TSB) in $1 \mathrm{~L}$ of distilled water. Next, serial dilutions of seed sludge were prepared by adding $1 \mathrm{~mL}$ of sample into $9 \mathrm{~mL}$ of sterile distilled water until a $10^{12}$ times dilution is 
obtained. Subsequently, $1 \mathrm{~mL}$ from each dilution number was then inoculated into vials containing TSB. This was done in triplicates for each dilution to enable comparison with 3tubes most probable number (MPN) table. The vials were then incubated under anaerobic condition for 8 days at $55^{\circ} \mathrm{C}$. To obtain the MPN of total anaerobes, each vial was first determined to be either positive if the mixture was cloudy or negative if the mixture was clear after incubation. The combination of positive and negative tubes was then compared against MPN table to obtain a corresponding MPN value ${ }^{[7]}$. In contrast, MPN for methanogens was obtained by detecting the presence of methane using biogas analyser (Binder Combimass Ga-m). Vials were marked as positive if methane is detected and negative otherwise. The combination of positive and negative tubes was compared against the same table as for total anaerobes. The cell survival of microbes was subsequently determined by equation (7).

$$
\text { Log Reduction }=\log \left(\frac{M P N_{\text {before dryting }}}{M P N_{\text {Gfter dryting }}}\right)
$$

\subsubsection{COD removal}

A $250 \mathrm{~mL}$ Schott Duran Bottle was set-up as bioreactor where $50 \mathrm{~mL}$ of rehydrated mixed culture was used to treat $150 \mathrm{~mL}$ of POME after $\mathrm{pH}$ adjustment by adding $1 \mathrm{~mol} / \mathrm{L}$ sodium bicarbonate. Supernatant was collected regularly for a period of 12 days from the bioreactor after allowing 30 minutes settling time. It was then analysed for COD level by following HACH Method 8000 which is USEPA approved for wastewater analyses (Standard Method 5220 D). The COD removal of the rehydrated sample was calculated using Equation (8).

$$
\text { COD Rentoval }=\frac{\left(C O D_{\text {inttial }}-C O D_{\text {final }}\right)}{\operatorname{COD}_{\text {inttial }}} \times 100 \%
$$

\subsubsection{Methane yield}

Daily monitoring of bioreactor was conducted over 12 days period to obtain both biogas volume $(\mathrm{mL})$ and methane composition $(\%)$. Biogas volume was measured by capturing the produced gas in an inverted measuring cylinder while its composition was obtained using biogas analyser Binder COMBIMASS ${ }^{\circ}$ Ga-m.

\section{Results and Discussion}

\subsection{Drying rate, effective moisture diffusivity, total drying time and EMC}

Tables 1 shows that low temperature drying using heat pump took longer time compared to high temperature drying using hot air circulation oven drying as heat pump was operated at drying temperature that is equal to- or below ambient temperature and thus relies on low relative humidity as the main driving force. Generally, higher temperature of drying air enables greater transfer of heat from air to water molecules in the mixed culture. This gives 
rise to higher rate of evaporation (i.e. drying rate) and hence shorter total drying time required for the sludge to achieve EMC. Air at higher temperature also has greater capacity to hold moisture and thus hotter air is able to remove more water molecules than colder air of the same flow rate. In terms of effective moisture diffusivity, the values of $\mathrm{D}_{\text {eff }}$ increased notably with increasing drying temperatures for both heat pump drying and hot air circulation oven drying. Lower relative humidity at high drying temperature promoted moisture concentration gradient between the surface of drying sample and its inner interstices, which stimulates the moisture diffusion from the interior of the sample to the surface and thus produced dried sludge with low EMC. Nevertheless, better survival of microorganism is achieved by drying at low temperature and relatively short drying time due to minimisation of heat and osmotic stresses ${ }^{[8]}$. Therefore, it is important to weigh over the importance of achieving high cell survivability over short drying time resulted from elevated drying temperature. Moreover, the performance of mixed culture in treating POME after subjected to drying process must also be considered.

Table 1. Average drying rate, effective moisture diffusivity, total drying time and EMC of heat pump and hot air circulation oven dried mesophilic mixed culture

\begin{tabular}{|c|c|c|c|c|}
\hline $\begin{array}{l}\text { Drying } \\
\text { Method }\end{array}$ & $\begin{array}{c}\text { Average Drying } \\
\text { Rate (R) } \\
\left(\mathrm{g} \mathrm{H}_{\mathbf{2}} \mathrm{O} / \mathrm{m}^{2} . \mathbf{s}\right)\end{array}$ & $\begin{array}{l}\text { Average Effective } \\
\text { Diffusivity (Deff) } \\
\quad\left(\times 10^{-8} \mathrm{~m}^{2} \mathrm{~s}^{-1}\right)\end{array}$ & $\begin{array}{c}\text { Total Drying } \\
\text { Time (h) }\end{array}$ & $\begin{array}{c}\text { EMC } \\
\left(\mathrm{g} \mathrm{H} \mathrm{H}_{2} \mathrm{O} / \mathrm{g}\right. \\
\text { dry solid) }\end{array}$ \\
\hline Heat pump $\left(22^{\circ} \mathrm{C}\right)$ & 4.67 & 0.85 & 26.6 & 0.148 \\
\hline Heat pump $\left(32^{\circ} \mathrm{C}\right)$ & 5.78 & 0.97 & 23.0 & 0.046 \\
\hline Oven $\left(40^{\circ} \mathrm{C}\right)$ & 8.57 & 3.39 & 7.5 & 0.034 \\
\hline Oven $\left(50^{\circ} \mathrm{C}\right)$ & 12.87 & 3.88 & 5.8 & 0.026 \\
\hline Oven $\left(60^{\circ} \mathrm{C}\right)$ & 19.41 & 4.25 & 4.5 & 0.017 \\
\hline Oven $\left(70^{\circ} \mathrm{C}\right)$ & 21.55 & 4.62 & 3.5 & 0.012 \\
\hline
\end{tabular}

\subsection{Cell survival, COD removal and methane yield}

According to Table 2, the lowest log reduction for methanogens and anaerobes were obtained from $22^{\circ} \mathrm{C}$-drying for heat pump drying with $1.4 \& 2.4$ and from $50^{\circ} \mathrm{C}$ for hot air circulation oven with $1.5 \& 5.6$, respectively. Generally, higher log reductions indicate that more cell deaths occur during the drying process. Higher cell survivability was found towards milder drying temperature was likely due to the nature of mesophilic mixed culture which thrives at $20-35^{\circ} \mathrm{C}$ combined with reduced thermal inactivation when drying was conducted at relatively lower temperatures ${ }^{[9]}$. As such, the mesophiles within mixed culture suffer from higher cell inactivation at higher temperature drying in a hot air circulation oven. As compared with mesophilic seed sludge, mesophilic mixed culture dried at the 
various drying temperatures still gives comparable average COD removals in the range of $46.8 \%$ to $55.3 \%$, with fairly similar trend with the preceding cell viability, where more favourable results were obtained with decreasing drying temperature. This is indicated in Table 3 where mixed culture dried at $22^{\circ} \mathrm{C}$ gave rise to higher COD removal as compared to other drying temperatures. In terms of methane yield, mesophilic mixed culture that was dried at $50^{\circ} \mathrm{C}$ in a hot air circulation oven produces highest yield at $37.6 \mathrm{~mL} \mathrm{CH}_{4} / \mathrm{g} \mathrm{COD}$ when compared with other drying temperatures. It is most likely that a balance between drying temperature and drying duration was reached at $50^{\circ} \mathrm{C}$-drying, producing dried sludge with moisture content that favours the survival of methanogens, eventually resulting in second highest values for both $\mathrm{N}_{\mathrm{M}}\left(\right.$ after $\mathrm{HP} 22^{\circ} \mathrm{C}$ ) and $\mathrm{N}_{\mathrm{M}} / \mathrm{N}_{\mathrm{A}}$ (after $60^{\circ} \mathrm{C}$ ) as illustrated in Table 2. Optimum moisture content as well as drying time are both directly affected by drying temperature and could influence the cell viability in mixed culture after drying ${ }^{[4]}$.

Table 2. Most probable number (MPN) and log reduction of mesophilic mixed culture following drying process

\begin{tabular}{ccccccc}
\hline \multirow{2}{*}{ Drying Technique } & \multicolumn{3}{c}{ Most Probable Number $\left(\mathbf{m l}^{-\mathbf{1}}\right)$} & & \multicolumn{2}{c}{ Log Reduction } \\
\cline { 2 - 4 } & $\begin{array}{c}\text { Methano } \\
\text { gens, } \boldsymbol{N}_{\boldsymbol{M}}\end{array}$ & $\begin{array}{c}\text { Anaerobes, } \\
\boldsymbol{N}_{\boldsymbol{A}}\end{array}$ & $\begin{array}{c}\boldsymbol{N}_{M^{\prime}} / \boldsymbol{N}_{\boldsymbol{A}} \\
(\%)\end{array}$ & & Methanogens & Anaerobes \\
\hline Mesophilic seed sludge & $9.30 \cdot 10^{1}$ & $1.99 \cdot 10^{12}$ & $4.67 \cdot 10^{-9}$ & & $\mathrm{n} / \mathrm{a}$ & $\mathrm{n} / \mathrm{a}$ \\
Heat Pump $\left(22^{\circ} \mathrm{C}\right)$ & $0.36 \cdot 10^{1}$ & $7.50 \cdot 10^{9}$ & $4.80 \cdot 10^{-8}$ & & 1.4 & 2.4 \\
Heat Pump $\left(32^{\circ} \mathrm{C}\right)$ & $0.24 \cdot 10^{1}$ & $1.15 \cdot 10^{9}$ & $2.08 \cdot 10^{-7}$ & & 1.6 & 3.2 \\
Oven $\left(40^{\circ} \mathrm{C}\right)$ & $0.16 \cdot 10^{1}$ & $2.90 \cdot 10^{6}$ & $5.52 \cdot 10^{-5}$ & & 1.8 & 5.8 \\
Oven $\left(50^{\circ} \mathrm{C}\right)$ & $0.29 \cdot 10^{1}$ & $4.60 \cdot 10^{6}$ & $6.30 \cdot 10^{-5}$ & & 1.5 & 5.6 \\
Oven $\left(60^{\circ} \mathrm{C}\right)$ & $0.21 \cdot 10^{1}$ & $2.30 \cdot 10^{6}$ & $9.13 \cdot 10^{-5}$ & & 1.6 & 5.9 \\
Oven $\left(70^{\circ} \mathrm{C}\right)$ & $0.20 \cdot 10^{1}$ & $3.60 \cdot 10^{6}$ & $5.56 \cdot 10^{-5}$ & & 1.7 & 5.7 \\
\hline
\end{tabular}

Table 3. COD removal and methane yield of mesophilic mixed culture before and after drying under heat pump and hot air circulation oven

\begin{tabular}{cccc}
\hline Drying Technique & COD Removal (\%) & & Methane Yield (mL CH4/g COD) \\
\cline { 1 - 1 } Mesophilic Seed Sludge & $67.4 \pm 9.8$ & & $44.1 \pm 10.5$ \\
Heat Pump $\left(22^{\circ} \mathrm{C}\right)$ & $55.3 \pm 8.9$ & & $17.9 \pm 1.74$ \\
Heat Pump $\left(32^{\circ} \mathrm{C}\right)$ & $52.8 \pm 5.6$ & & $14.1 \pm 1.66$ \\
Oven $\left(40^{\circ} \mathrm{C}\right)$ & $52.9 \pm 2.7$ & $53.5 \pm 3.4$ & $37.9 \pm 1.55$ \\
Oven $\left(50^{\circ} \mathrm{C}\right)$ & $50.2 \pm 4.5$ & & $22.3 \pm 3.61$ \\
Oven $\left(60^{\circ} \mathrm{C}\right)$ & $46.8 \pm 7.0$ & & $37.2 \pm 2.90$ \\
Oven $\left(70^{\circ} \mathrm{C}\right)$ & &
\end{tabular}


Preservation of mesophilic mixed culture for anaerobic palm oil mill effluent treatment by convective drying methods

\section{Conclusion}

Heat pump drying of mixed culture mesophilic sludge takes considerably longer time to reach EMC as compared to hot air circulation oven drying at elevated temperature. Nevertheless, in term of quality analysis, heat pump dried mesophilic mixed culture at mild temperature $\left(22^{\circ} \mathrm{C}\right)$ gave rise to the best methanogenic survival, anaerobic survival, and COD removal among of all. The highest methane yield was produced by hot air circulation oven dried mesophilic mixed culture at $50^{\circ} \mathrm{C}$. It might appear that either one of these two drying conditions could be considered as the most suitable drying condition for mixed culture mesophilic sludge depending on the desired outcome. However, hot air circulation oven drying at $50^{\circ} \mathrm{C}$ could be more practical in industrial setting as drying duration is shorter.

\section{References}

[1] Choi, W.H.; Shin, C.H.; Son, S.M.; Ghorpade, P.A.; Kim, J.J.; Park, J.Y. Anaerobic treatment of palm oil mill effluent using combined high-rate anaerobic reactors. Bioresource technology 2013, 141, 138-44.

[2] Li, J.; Fraikin, L.; Salmon, T.; Plougonven, E.; Toye, D.; Léonard, A.; Convective drying behavior of sawdust-sludge mixtures in a fixed bed. Drying Technology 2016, 34 (4), 395-402.

[3] Chávez, B.E.; Ledeboer, A.M. Drying of Probiotics: Optimization of Formulation and Process to Enhance Storage Survival. Drying Technology 2007, 25 (7-8), 1193-1201.

[4] Zayed, G.; Roos, Y.H. Influence of trehalose and moisture content on survival of Lactobacillus salivarius subjected to freeze-drying and storage. Process Biochemistry 2004, 39 (9), 1081-1086.

[5] Tambunan, A.H. Freeze Drying Characteristics of Medicinal Herbs. Drying Technology 2001, 19 (2), 325-331.

[6] Kasali, G.B.; Senior, E.; Watson-Craik, I.A. Preliminary investigation of the influence of $\mathrm{pH}$ on the solid-state refuse methanogenic fermentation. Journal of Applied Bacteriology 1988, 65 (3), 231-239.

[7] Man, J.C. MPN tables, corrected. European Journal of Applied Microbiology and Biotechnology 1983, 17 (5), 301-305.

[8] Morgan, C.A.; Herman, N.; White, P.A.; Vesey, G. Preservation of micro-organisms by drying; a review. Journal of Microbiological Methods 2006, 66 (2), 183-93.

[9] Perdana, J.; Bereschenko, L.; Fox, M.B.; Kuperus, J.H.; Kleerebezem, M.; Boom, R.M.; Schutyser, M.A.I. Dehydration and thermal inactivation of Lactobacillus plantarum WCFS1: Comparing single droplet drying to spray and freeze drying. Food Research International 2013, 54 (2), 1351-1359. 